\title{
Study on HDPE Effect on Rutting Resistance of Binder
}

\author{
Benjamin Piromanski®, Amin Chegenizadeh *, Nuha Mashaan $₫$ and Hamid Nikraz \\ Department of Civil Engineering, School of Civil and Mechanical Engineering, Curtin University, Kent Street, \\ Bentley, WA 6102, Australia; Benjamin.Piromanski@student.curtin.edu.au (B.P.); \\ nuhasmashaan@postgrad.curtin.edu.au (N.M.); h.nikraz@curtin.edu.au (H.N.) \\ * Correspondence: amin.chegenizadeh@curtin.edu.au
}

Received: 29 July 2020; Accepted: 28 August 2020; Published: 2 September 2020

\begin{abstract}
Literature has shown positive results to using waste plastic as an alternative source for PMBs where considerable interest in using waste High-density polyethylene (HDPE) has been highlighted on improving rutting resistance. Most importantly, using a waste polymer for an application has benefits (i.e., maintenance, environmental) by improving the durability and quality of our roads and by avoiding polymers from landfill or incineration. This research uses the Multiple Stress Creep Recovery (MSCR) test to assess the performance of a binder modified with waste HDPE polymer. The outcomes of this research highlights that a HDPE content of $2-4 \%$ shows a substantial increase in rutting resistance and an improvement in elastic recovery. The elastic recovery reported does improve from previous research results however it does underperform in comparison with the Styrene butadiene styrene (SBS) polymer counterpart. Furthermore, it can be indicated by the aging index that a HDPE content of greater than $4 \%$ can be detrimental to the aging effects leading to fatigue cracking. It is recommended that a combination of both waste HDPE and an elastomeric polymer such as crumb rubber is to be used in future test work to improve the elastic recovery and address the effects of fatigue cracking.
\end{abstract}

Keywords: waste plastic; polymer modified binder; HDPE; rutting; permanent deformation; MSCR test

\section{Introduction}

\subsection{Background}

Rutting is one of the main issue in pavement engineering [1]. Rutting, also referred to as permanent deformation is a common occurrence in the North West of Australia where pavement is subjected to higher trafficable loading from an increase usage of road trains under hot climatic conditions [2]. The main cause for rutting is apparent when a binder becomes sensitive to stress at high temperatures due to the softness of the binder [3]. Thus, it is important to investigate the temperature vulnerability of a binder in order to address rutting resistance [4].

Polymer Modified Binder's (PMBs) are a popular way to enhance the binder's performance against both fatigue and rutting. The application of polymer-modified bitumen enhances the pavement's service life length, especially in severe conditions such as parking areas tolerating heavy traffic loads, deformed road base, and stress-relieving interlayer. However, a modified binder is by no means a new phenomenon. It has been proven to meet the requirements for optimal performance in modern pavement construction and coatings; also, it appears to be a practical, logical, and economical approach compared to other approaches $[3,5]$.

Polymer modified bituminous mixture has an extensive choice of applications nowadays in most countries around the world. Adding polymer to the bituminous mixture increases its stiffness and improves its non-susceptibility to temperature fluctuations in different regions and climates. 
This feature, in turn, raises the level of resistance of the mixture to rutting. Additionally, it is believed that high polymer content in asphalt modification could provide more benefits in terms of improving the performance properties of pavement [5]. In Western Australia, the polymer of choice commonly used is either SBS or crumb rubber where its elastomeric properties have been proven to enhance a binders resistance against fatigue [2]. However, literature suggested that elastomeric polymers do not adequately rectify the temperature vulnerability of a binder compare to plastomer type polymers such as Ethylene-vinyl acetate (EVA) which is a popular choice to enhance resistance against rutting. However, it is good to be noted that polymers from virgin origins are expensive to produce and have its obvious negative impacts on the environment [6-10].

Majority of Australia's bitumen is sourced from international suppliers [11], where over $80 \%$ is imported from East Asian markets [12]. Several studies have indicated the loss of quality of bitumen from international markets in comparison with Australian manufactured bitumen [13,14]. The loss of quality is primarily due to the reduction of the asphaltene content throughout the bituminous medium resulting in a lower viscous bitumen and hence a 'softer' bitumen [15]. Therefore, one can say the reduction of quality has been a contributing factor to making the need to use PMBs inevitable.

AGPT/T190, The Australian PMB specification, consistency $6 \%$ at $60^{\circ} \mathrm{C}$ is used for Elastometer test parameter, to rank the rutting resistance of a PMB. Although, the Elastometer parameter has been verified by several studies $[1,16]$, it is of the Authors opinion that the parameter will be limited at high service temperatures to measure and predict the temperature susceptibility of PMB. Recent developments with the U.S. Superpave specifications has recently adopted the Multiple Stress Creep Recovery (MSCR) test to evaluate a binder and grade its in-situ rutting performance [17]. The MSCR test specification, listed as AASHTO M332, provides a high temperature binder specification that has been proven to assess the temperature susceptibility and hence the rutting resistance against the non-recoverable compliance parameter $\left(\mathrm{J}_{\mathrm{nr}}\right)$. Previous research has indicated that the $\mathrm{J}_{\mathrm{nr}}$ correlates better to in-situ rutting resistance in comparison to the Strategic Highway Research Program (SHRP) rutting parameter $\left(G^{*} / \sin \delta\right)[18-20]$.

Alternatively, international studies have shown positive results to enhancing the performance of a binder that often matches if not improving the performance of virgin polymers [8,21-34]. Costa et al. [9] had highlighted positive results in using waste HDPE to modify a binder's resistance against rutting. However, it is worth noting Costa et al. [9] emphasized that HDPE modified binder caused with poor elastic recovery that may lead to potential cracking from fatigue failure. Research in Waste Polymer Modified Binder (WPMB) in Australia is limited, test work to validate the compatibility of using waste HDPE polymer is required prior to implementing in the road networks of Australia.

Most importantly using a waste polymer has environmental benefits [35]. With the recent prohibition of export of plastic from China [36], Australia's recycling rate is on the decline where exports to China has previously accounted for roughly one-third of the total recycled plastics [37]. Highlighting the quantity of plastic waste by polymer type, Statistics shows that HDPE is a dominant waste plastic, providing a substantial available resource as a WPMB [35].

The previous research of WPMBs provided this test work the guidance selecting the polymer type and mixing requirements. Mixing requirements have been noted to be critical to the performance of a WPMB [32]. In addition it was highlighted by Kalantar et al. [7] that the mixing temperature and duration will depend on the type of polymer. A summary of the previous research that has undertaken waste HDPE polymer is listed Table 1 corresponding to the resulting outcome. It is worthy to note that previous research indicates improved performance from smaller particle size, long mixing duration, high mixing velocity at high temperatures.

As shown in the Table 1, that there are different condition mix (time, temperature and rpm speed mix) due to the difference in the bitumen type and application of mixtures, as well as type of polymer. The studies in Table 1 indicated that the longer mix duration of $6 \mathrm{~h}$ results in poor dispersion, however, mixing time of 30-90 min could essentially provide modified binder with better rutting resistance. 
The novelty of the current work is that using local WA plastic waste to improve the binder properties before and after aging. Also, the study focuses on filling the gap of knowledge related to rutting performance based on the modified binder characterises using bitumen grade C170. Most importantly that the study is novel in term of there is no current study has been conducted to improve the $\mathrm{C} 170$, which is primarily used for spray sealing applications, using waste HDPE. Using waste plastic has its visible environmental profits together with the reduction of cost for PMB application. On the other hand, it cannot be expected that waste HDPE plastic would be well-suited with bitumen modification in Australia without conducting laboratory afford investigating the rheological test and modified binder performance.

Table 1. HDPE Bitumen Mixing recommendation.

\begin{tabular}{ccccc}
\hline Study & $\%$ & Mixing & $\begin{array}{c}\text { Size } \\
\mathbf{m m}\end{array}$ & Outcome \\
\hline$[32]$ & 4 & $30 \mathrm{~min} @ 165^{\circ} \mathrm{C} 200 \mathrm{rpm}$ & $0.42-2$ & High rutting resistance \\
Poor Dispersion \\
{$[38]$} & $1-3$ & $6 \mathrm{~h} @ 180{ }^{\circ} \mathrm{C}(1800 \mathrm{rpm})$ & - & Better Performance \\
{$[9]$} & 4 & $90 \min @ 160{ }^{\circ} \mathrm{C}$ & - & High rutting resistance \\
\hline
\end{tabular}

\subsection{Objectives}

The aim of this research is to investigate the effect of HDPE waste polymer to enhance the rutting performance of a bituminous binder. The objectives of this research are summarised as follows;

- Investigate the possibility that HDPE waste polymer inclusion on rutting behaviour of C170 binder using the MSCR test

- Evaluate waste HDPE modified binder as a sustainable alternative

- Investigate the aging impact of waste HDPE modified binder in terms of resistance to permanent deformation

\section{Materials and Methods}

\subsection{Experimental Program}

The experimental program used throughout the experiment used grade $\mathrm{C} 170$ bitumen in accordance with AS2008-2013 [39] using increments of 2\% HDPE content capped at a maximum of $8 \%$. Both a clean (unmodified) C170 and a PMB grade S35E was used as a reference and benchmark throughout the experiment. The experimental program is shown in Table 2, and the average of 3 samples/reading of each mix Id was used through the laboratory work. Furthermore, the test temperature is orientated around $64{ }^{\circ} \mathrm{C}$ similar to the rheological test work conducted by Vo [14]. However, in order to evaluate the temperature susceptibility of the WPMB, a wide range of temperatures were chosen and listed as $58,60,64,70,76$ and $82{ }^{\circ} \mathrm{C}$. Temperature increments were based on the specifications set out in AASHTO M332 [40]. The AASHTO M332 [40] performance grading specification allows the recorded $\mathrm{J}_{\mathrm{nr}}$ parameter to be graded against an equivalent traffic loading.

Table 2. Test Plan.

\begin{tabular}{cc}
\hline \multicolumn{2}{c}{ Unaged Samples } \\
\hline Mix Id & Mix Description \\
\hline Mix U-S35E & S35E PMB \\
Mix U-HDPE-8 & C170 + 8\% HDPE \\
Mix U-HDPE-6 & C170 + 6\% HDPE \\
Mix U-HDPE-4 & C170 + 4\% HDPE \\
Mix U-HDPE-2 & C170 + 2\% HDPE \\
Mix U-C170 & unmodified C170 \\
\hline
\end{tabular}


Table 2. Cont.

\begin{tabular}{cc}
\hline \multicolumn{2}{c}{ Aged Samples } \\
\hline Mix A-S35E & S35E PMB \\
Mix A-HDPE-8 & C170 + 8\% HDPE \\
Mix A-HDPE-6 & C170 + 6\% HDPE \\
Mix A-HDPE-4 & C170 + 4\% HDPE \\
Mix A-HDPE-2 & C170 + 2\% HDPE \\
Mix A-C170 & unmodified C170 \\
\hline
\end{tabular}

\subsection{Material Selection}

The waste HDPE polymer utilized all through the investigation included utilized clothing containers and water stockpiling tanks, as appeared in Figure 1. To guarantee consistency, HDPE items utilized showed the ASTM International Resin Identification Coding (RIC) System. All waste HDPE had labels removed prior to the sample preparation. The used HDPE can be seen in Figure 1.

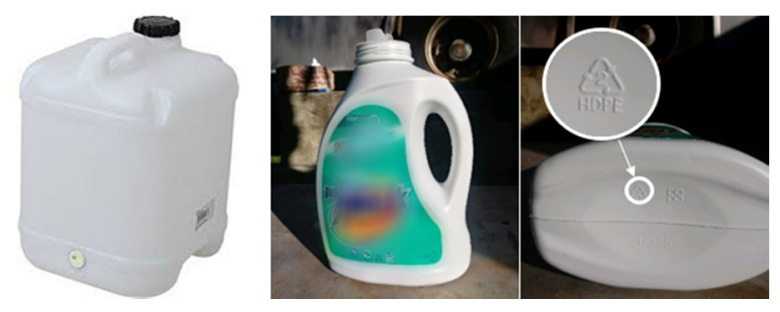

Figure 1. Used HDPE Polymer.

Bitumen grade $\mathrm{C} 170$ was used throughout the experiment given that $\mathrm{C} 170$ is primarily used for spray sealing applications. Spray seals account for more than $50 \%$ of the bitumen used in the road construction industry [11]. Furthermore, $70 \%$ of Australian sealed roads and majority of the roads in the North West of Australia comprise of spray seal applications [41]. Bitumen grade C170 is as per the Australian Standard AS2008-2013 [39]. One of the popular PMB grades used in the spray seal industry is S35E (Main Roads WA) [42,43].

\subsection{Sample Preparation}

\subsubsection{Waste HDPE Polymer Preparation}

The procedure utilised a $54 \mathrm{~mm}$ saw drill bit to produce fine shavings as shown in Figure 2. Waste HDPE particle sizes less than $0.425 \mathrm{~mm}$ were collected and used for the test work.

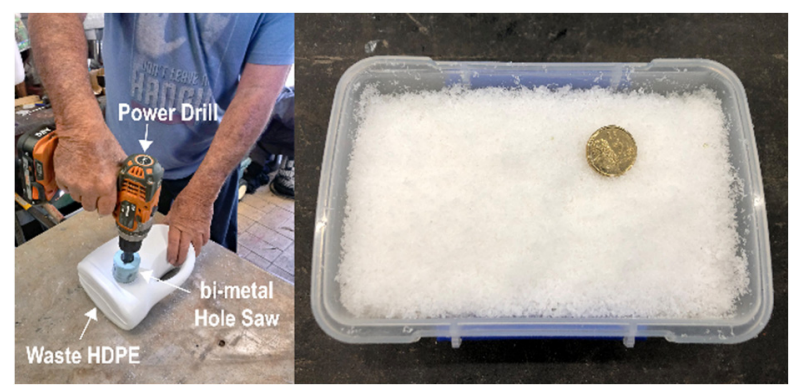

Figure 2. Sample Preparation (Image Courtesy: Benjamin Piromanski).

\subsubsection{Bitumen Sample Mixing}

As outlined in Table 1, the mixing requirements used in previous WPMB studies show a trend that a smaller particle size, high mixing velocity and temperature is imperative to achieving best results when mixing waste HDPE polymer. The blending prerequisites utilized for this examination is 
illustrated in Table 3. The apparatus used for the experiment as shown in Figure 3. It is important to point that the SBS polymer modified bitumen (S35E) was supplied directly from the crude oil refinery (from SAMI bitumen's supplier).

Table 3. Bitumen Mixing characteristics.

\begin{tabular}{cc}
\hline Duration & $40 \mathrm{~min}$ \\
\hline Velocity & $2500 \mathrm{rpm}$ \\
\hline Temperature & $180{ }^{\circ} \mathrm{C}$ \\
\hline
\end{tabular}

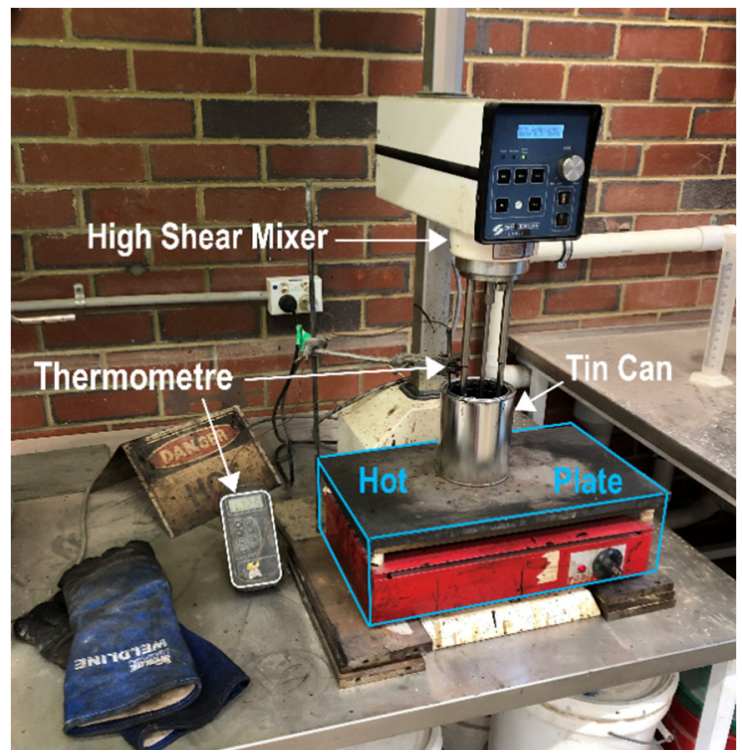

Figure 3. Bitumen Mixing Apparatus (Civil Engineering Laboratory, Curtin University, Image Courtesy: Benjamin Piromanski).

\subsection{Methods}

\subsubsection{Multiple Stress Creep Recovery (MSCR) Test}

The MSCR Test, as outlined in AASHTO M332, is currently the preferred method to determine a binder's resistance against rutting [17]. The MSCR test utilizes a generally acknowledged creep and recovery test that estimates both the binders non-recoverable creep (NRC) compliance and elastic recovery. The non-recoverable creep compliance $\left(\mathrm{J}_{\mathrm{nr}}\right)$ at $3.2 \mathrm{kPa}$ has been a widely accepted parameter to correlate a binder with in-situ rutting resistance among the literature [18-20]. Originating in the US and becoming the standard binder test procedure [44]. In addition, the MSCR test has benefits over other test procedures such as testing a binder blind regardless if the binder is modified or not.

\subsubsection{Rolling Thin Oven (RTFO) Test}

The Rolling Thin Oven (RTFO) Test is carried out to replicate the aging process for when the bitumen leaves the depot and is laid on-site. The RTFO test was in accordance with A/NZS 2341.10:2015 [45]. Both aged and unaged binders will provide insight in to the aging effects that waste HDPE polymer has on bitumen by using the aging index [46,47]. 


\section{Results and Discussion}

\subsection{Non-Recoverable Creep Compliance}

The AASHTO M332 performance grading is overlayed for reference. Figure 4 shows aged non-recoverable compliance results.

A huge increasing of NRC was seen with the inclusion of waste HDPE. The $2 \%$ HDPE content shows a similar rutting resistance to the S35E PMB. Also, it can be observed that there is a huge improvement from 2-4\% HDPE. In comparison with Costa et al. [9], there is agreeance that HDPE improves rutting resistance. However, noting that the HDPE content used in Costa et al. [9] was 5\%, improved results of rutting resistance are evident in this test work. As displayed in Figure 4, using waste plastic shows improved rutting resistance with an acceptable range of elastic behavior through the different series of test temperature. This results is in similar trend to the previous findings [9], however; luck of elastic behavior found at $60{ }^{\circ} \mathrm{C}$. This phenomenan could be explained by the variotion of the temperaturte increase duting the mixing stage.

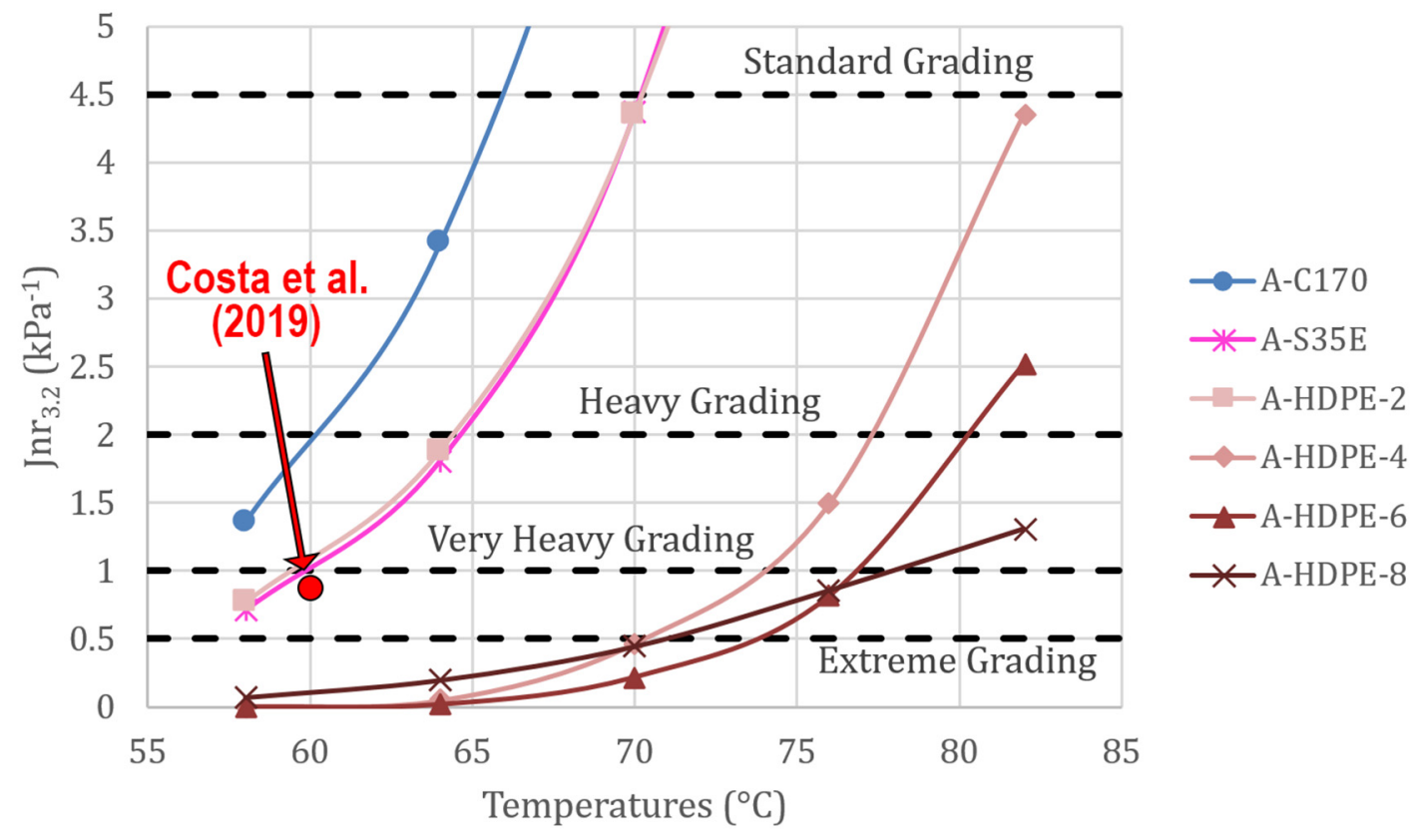

Figure 4. Results of aged non-recoverable compliance.

\subsection{Elastic Recovery}

Figure 5 shows the recoverable strain graphed against the $\mathrm{J}_{\mathrm{nr}}$ at $3.2 \mathrm{kPa}$ stress. Similarly, the performance grading criteria from AASHTO M332 is overlayed for reference. The polymer modification curve (PMC) is also shown as a theoretical line indicating the minimum level of elastic recovery required for the binder to be considered adequately modified. For adequate levels of elastic recovery, the average recovery should be above the PMC [48]. The results show that all samples fall short of the requirement to be considered adequately modified except for a HDPE content of $4 \%$ where adequate elastic recovery is present corresponding to temperatures less than $68^{\circ} \mathrm{C}$. As expected, the S35E PMB showed higher levels of elastic recovery throughout the test procedure. It is interesting to note that an adequate level of elastic recovery was present at high $\mathrm{J}_{\mathrm{nr}}$ values which was not reported in previous WPMB studies. 


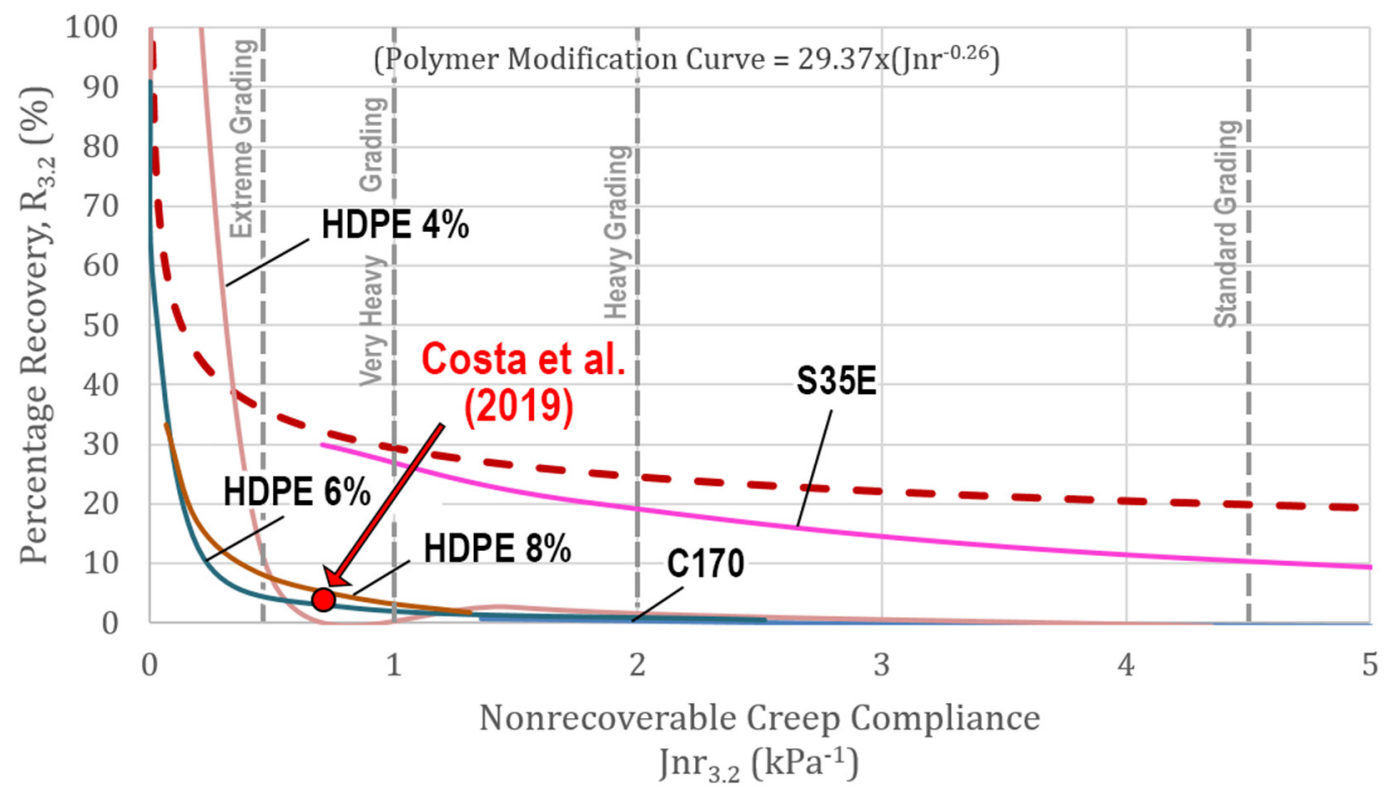

Figure 5. Aged binder indication of elastic response.

\subsection{Durability Performance: Aging Index}

Equation (1) was used in this section. Noting that the NRC compliance represents a harder binder at lower values, high values of the aging index is expected to show a decrease in the effect of aging and low values of the aging index are to represent the contrary. As shown in Figure 6, the C170 binder was less effective on aging in $2 \%$ HDPE content. However, oxidative effects of hardening is enhanced by increasing in HDPE. The aging index for S35E PMB was not shown in Figure 6 for clarity, however it was found there was little change in aging in comparison with the $\mathrm{C} 170$ binder.

$$
\text { Aging Index }=\frac{P_{\text {aged }}}{P_{\text {unaged }}}
$$

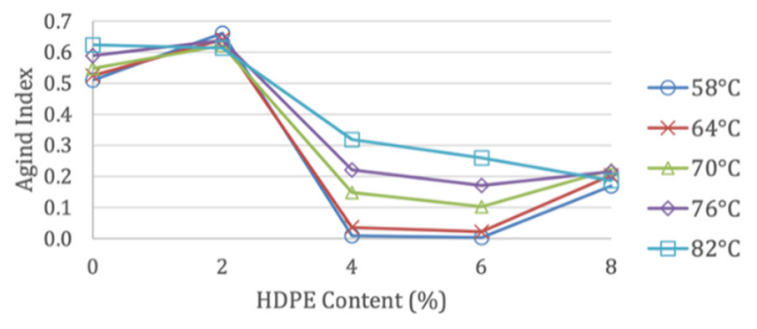

Figure 6. Aging index vs. HDPE content.

As mentioned in the previous studies [40,46,49], testing and investigating the aging effect on binder's properties is of a great impotence. This importance related to the fact that aging has a vital impact on the binder's properties in term of physical-rheological and chemical properties [46,49]. As an overall indication, a judgement of the stiffness increment is displayed in Figure 7. The decreases in non-recoverable compliance following the short term aging proves an agreement with previous study [46] that aging affects the physical and stiffness properties of the bitumen. 


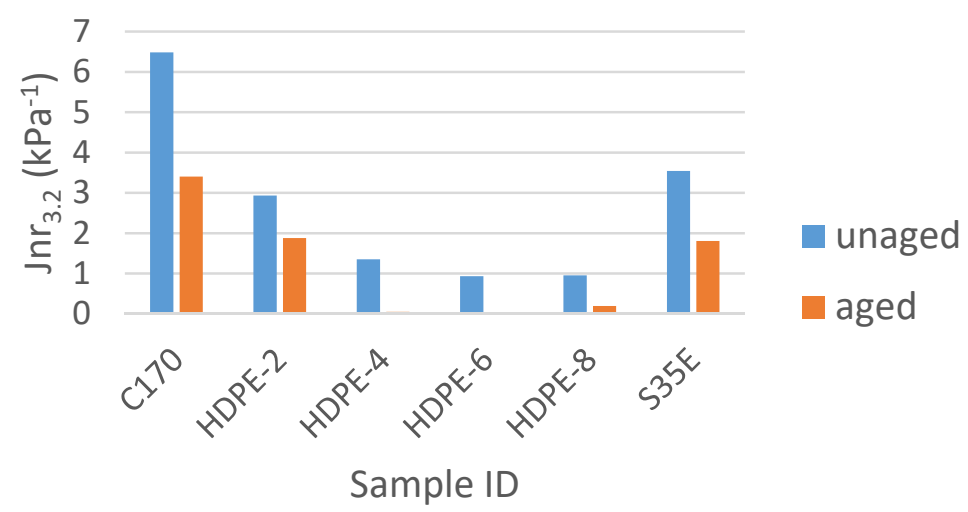

Figure 7. Impact of aging on non-recoverable compliance of different binders.

\subsection{Performance Grading}

As can be seen from the results of Figures 4 and 5, that the waste HDP samples agreed with the standard performance of AASHTO M332 (AASHTO 2014) [40] in regards of non-recoverable compliance and elastic behavior. Results at high test temperature shows that the control binder of C170 has less performance, and, as such was unsuccessful. Similarly trend happened to the PMA S35E, as it shows less performance at high temperature [49]. This results supported by what have been stated in the literature review as rutting becomes an issue of Western Australia. From Figures 4 and 5 , it can be shown that both of C170 and S35E have less performance grading and as such leading to an issue in temperature susceptibility. From above, it's obvious that waste plastic HDPE samples have the promising role in improving the rutting resistance of the Australian's bitumen and improve the elastic response at high level of temperature.

\subsection{Data Analysis}

\subsubsection{Empirical Relationship}

It was found that a strong correlation between 0 to $4 \%$ HDPE content was established throughout all temperatures. The coefficient factors $\gamma_{1}$ and $\gamma_{2}$ were found to account for the temperature variation as shown in Equations (2) and (3), respectively. Equation (4) is employed to calculate the NRC compliance of the percentage of waste HDPE polymer $(n)$ corresponding to the operating temperature (T) in ${ }^{\circ} \mathrm{C}$. Equation (4) is plotted in Figure 8 for clarity.

$$
\begin{aligned}
\gamma_{1} & =0.0007 e^{0.1264 T} \\
\gamma_{2} & =0.0005 e^{0.1322 T} \\
J n r_{3.2} & =\gamma_{1} n+\gamma_{2} 1.3867
\end{aligned}
$$

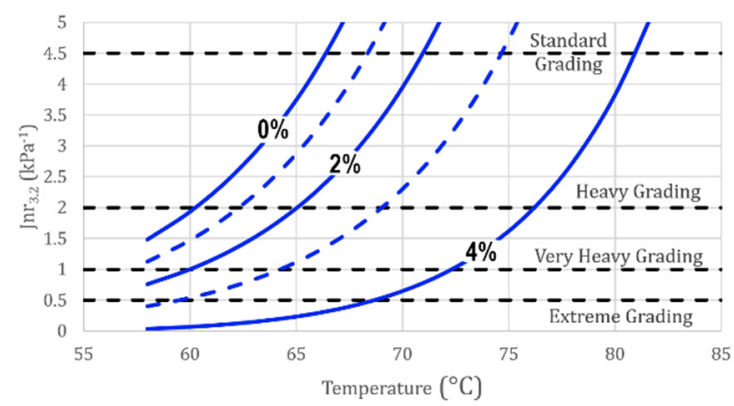

Figure 8. HDPE content and test temperature empirical relationship. 


\subsubsection{Data Analysis: Non-Recoverable Compliance and Waste HDPE Content Relationship}

As can be seen in the non-recoverable compliance section results that waste plastic HDPE has the ability to enhance the rutting resistance of the modified binder.

Using the collected data from the laboratory work, Figure 9 and Table 4 illustrated the correlation between the non-recoverable compliance and the content of waste HDPE binders. As can be seen in Figure 9, an obvious correlation between the two variables with good $\mathrm{R}^{2}$ values. Constant and liner regression relationship is illustrated in Table 4 , and as can be seen that HDPE content of $0-4 \%$ was liner with $\mathrm{R}^{2} 0.99$, however; samples of HDPE content of $4-8 \%$ show non-liner regression with $\mathrm{R}^{2}$ less than 0.99 . This result and variation can be attributed to the impact of high content of plastic (up to $8 \%$ ) in bitumen which could possible changes in the non-recoverable compliance and elasticity of the binder. Moreover, as a trial a polynomial correlation was employed into data and the outcome indicated that it was not as well as the linear correlation for 0 to $4 \%$ HDPE dosage [49].

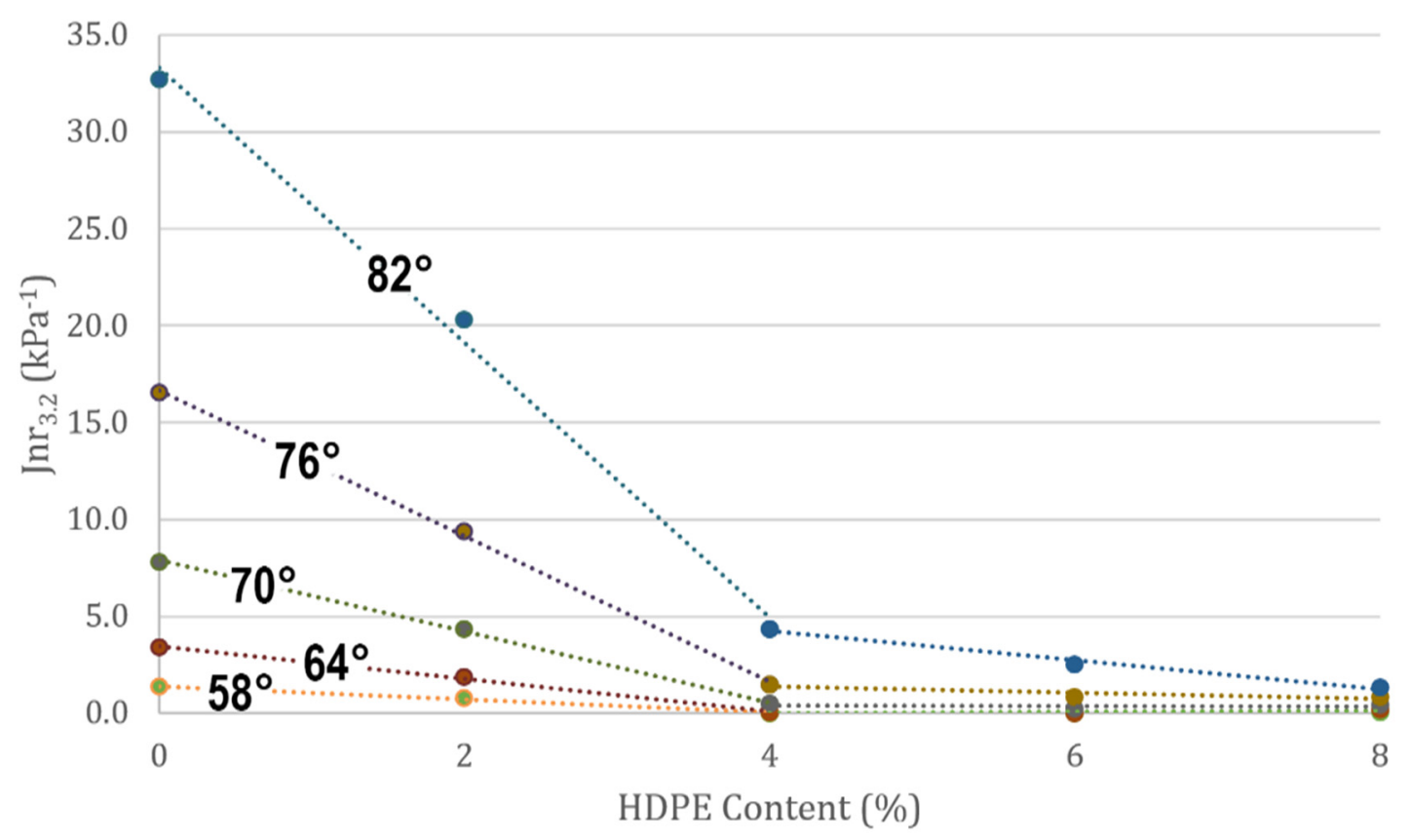

Figure 9. The correlation of Jnr (non-recoverable compliance and waste HDPE content.

Table 4. Data analysis and liner regression between waste HDPE content and the non-Recoverable Compliance.

\begin{tabular}{ccccc}
\hline \multirow{2}{*}{ Temperature $\left({ }^{\circ} \mathbf{C}\right)$} & \multicolumn{2}{c}{ HDPE Content 0-4\% } & \multicolumn{2}{c}{ HDPE Content 4-8\% } \\
\cline { 2 - 5 } & Line of Best Fit & $\mathbf{R}^{\mathbf{2}}$ & Line of Best Fit & $\mathbf{R}^{\mathbf{2}}$ \\
\hline 58 & $\mathrm{~J}_{\mathrm{nr} 3.2}=-0.3385 \mathrm{x}+1.3867$ & 0.995 & $\mathrm{~J}_{\mathrm{nr} 3.2}=0.0156 \mathrm{x}-0.0693$ & 0.709 \\
64 & $\mathrm{~J}_{\mathrm{nr} 3.2}=-0.8383 \mathrm{x}+3.4532$ & 0.997 & $\mathrm{~J}_{\mathrm{nr} 3.2}=0.0364 \mathrm{x}-0.1308$ & 0.610 \\
70 & $\mathrm{~J}_{\mathrm{nr} 3.2}=-1.8354 \mathrm{x}+17.8812$ & 0.999 & $\mathrm{~J}_{\mathrm{nr} 3.2}=-0.0061 \mathrm{x}+0.4138$ & 0.008 \\
76 & $\mathrm{~J}_{\mathrm{nr} 3.2}=-3.7643 \mathrm{x}+16.6640$ & 0.999 & $\mathrm{~J}_{\mathrm{nr} 3.2}=-0.1588 \mathrm{x}+2.0084$ & 0.701 \\
82 & $\mathrm{~J}_{\mathrm{nr} 3.2}=-7.0868 \mathrm{x}+33.2880$ & 0.9949 & $\mathrm{~J}_{\mathrm{nr} 3.2}=-0.7600 \mathrm{x}+7.2887$ & 0.986 \\
\hline
\end{tabular}

\section{Conclusions}

It can be summarised that HDPE polymer enhanced the bituminous binder rutting resistance. However, the elastic response was reduced with the increase in NRC compared to S35E PMB. Furthermore both rutting and elastic recovery showed improvement for HDPE content of $4 \%$ at temperatures of $68{ }^{\circ} \mathrm{C}$. This is a promising result given that operating temperatures of $68{ }^{\circ} \mathrm{C}$ are common in hot climatic conditions. 
An important consideration to the success of the results throughout the experiment can be contributed to the mixing conditions and polymer particle size throughout. It is recommended that the mixing velocity and duration is to be increased to further improve the results. Although it must be noted to limit the temperature of mixing to $200{ }^{\circ} \mathrm{C}$ to mitigate the bitumen from burning.

The aging index indicates that a high waste HDPE content of greater than $4 \%$, demonstrates excessive hardening which will possibly result in fatigue cracking. Interestingly, a HDPE content of $2 \%$ shows little effect on the oxidative effect on aging. Therefore, based on the data from this experiment, a HDPE content ranging from $2-4 \%$ is an acceptable range that compliments rutting resistance, elastic recovery and the effects of aging. As for the AASHTO performance specification, it can be shown that both of C170 and S35E have less performance grading and as such leading to an issue in temperature susceptibility. From above, it's obvious that waste plastic HDPE samples have the promising role in improving the rutting resistance.

Analysis of the storage stability was not conducted throughout the experiment however, it was found that segregation was observed for all waste HDPE samples throughout storage. Improved mixing requirements or increasing heating could possibly mitigate the effects of segregation.

Data analysis shows a good relationship among the elastic response $\left(\mathrm{J}_{\mathrm{nr} 3.2}\right)$ and plastic content, which can be established as a predicate tool of the modified binder performance and its ability to resist rutting.

As per recommendation, it is advised to do the following, testing the long term aging of the binder using the Pressure Aging Vessel (PAV), and testing the rheological properties using different mix settings. And produce asphalt mix samples/beams to testing the rutting and fatigue performance of HDPE-modified asphalt mixture.

Author Contributions: Conceptualization, B.P., A.C.; methodology, B.P., A.C., N.M., H.N.; validation, B.P., A.C., N.M.; formal analysis, B.P., A.C.; investigation, B.P., A.C.; resources, A.C., H.N.; data curation, B.P., A.C.; writing-original draft preparation, B.P., A.C., N.M., H.N.; writing-review and editing, B.P., A.C., N.M., H.N.; visualization B.P.; supervision, A.C., H.N.; project administration, A.C., H.N. All authors have read and agreed to the published version of the manuscript.

Funding: This research received no external funding.

Acknowledgments: The Author would like to thank the contribution of the Laboratory technical staff Darren Isaac in supporting this research during the experimental process. In addition, the author would like to acknowledge the contribution from the School of Civil and Mechanical Engineering, Curtin University. This paper extracted from first author's research thesis.

Conflicts of Interest: The authors declare no conflict of interest.

\section{References}

1. Urquhart, R.; Budija, M.; Wilson, G. Investigations into the relationship between binder consistency/underlying viscosity and asphalt rutting. In Proceedings of the 24th ARRB Conference, Melbourne, Australia, 13-15 October 2010.

2. Leach, R. A Brief History of Bituminous Surfacings in Western Australia. J. Aust. Geomech. Soc. 2015, 50, 17.

3. D'Angelo, J.A. The Relationship of the MSCR Test to Rutting. Road Mater. Pavement Des. 2009, 10 (Suppl. 1), 61-80. [CrossRef]

4. $\quad$ Oliver, J.; Tredrea, P.; Witt, P. Relationships between binder properties and asphalt rutting. In Proceedings of the Combined 18th ARRB Transport Research Conference and Transit New Zealand Land Transport Symposium, Christchurch, New Zealand, 2-6 September 1996.

5. Habbouche, J.; Haji, E.Y.; Sebaaly, P.E.; Piratheepan, M. Acritical review of high polymer-modified aspahlt binders and mixtures. Int. J. Pavement Eng. 2020, 21, 686-702. [CrossRef]

6. Polacco, G.; Berlincioni, S.; Biondi, D.; Stastna, J.; Zanzotto, L. Asphalt modification with different polyethylene-based polymers. Eur. Polym. J. 2005, 41, 2831-2844. [CrossRef]

7. Kalantar, Z.N.; Karim, M.R.; Mahrez, A. A review of using waste and virgin polymer in pavement. Constr. Build. Mater. 2012, 33, 55-62. [CrossRef] 
8. Casey, D.; McNally, C.; Gibney, A.; Gilchrist, M.D. Development of a recycled polymer modified binder for use in stone mastic asphalt. Resour. Conserv. Recycl. 2008, 52, 1167-1174. [CrossRef]

9. Costa, L.M.B.; Silva, H.M.R.D.; Peralta, J.; Oliveira, J.R.M. Using waste polymers as a reliable alternative for asphalt binder modification-Performance and morphological assessment. Constr. Build. Mater. 2019, 198, 237-244. [CrossRef]

10. García-Morales, M.; Partal, P.; Navarro, F.J.; Martínez-Boza, F.; Gallegos, C.; González, N.; González, O.; Muñoz, M.E. Viscous properties and microstructure of recycled eva modified bitumen. Fuel 2004, 83, 31-38. [CrossRef]

11. Neaylon, K. Update on the Australian Bitumen Market. In Proceedings of the 9th Asian Bitumen Conference 2013, Jakarta, Indonesia, 25-27 September 2013.

12. Department of the Environment and Energy. Australian Petroleum Statistics; Department of the Environment and Energy: Canberra, Australia, 2019.

13. Austroads. The Results of Testing Overseas Bitumen; No.: AP-T110/08; Austroads: Sydney, Australia, 2008.

14. Vo, K. The performance of polymer modified bitumen inrelation to bitumen quality. In Proceedings of the ARRB Conference, Melbourne, Australia, 16-18 November 2016.

15. Srivastava, A.; van Rooijen, R. Innovation Road Rehabilitation and Recycling Technologies. In Proceedings of the Pavement Seminar for the Middle East and North Africa Region, Amman, Jordan, 24-26 October 2000.

16. Austroads. Laboratory Study on Relationship between Binder Properties and Asphalt Rutting; 2010 Report No.: AP-T164/10; Austroads: Sydney, Australia, 2010.

17. The Fedral Highway Adminstration. The Multiple Stress Creep Recovery (MCSR) Procedure; 2011 Report No.: FHWA-HIF-11-038; The Fedral Highway Adminstration: Washington, DC, USA, 2011.

18. Albritton, G.; Barstis, W.; Crawley, A. Polymer Modified Hot Mix Asphalt Field Trial; Mississipi Department of Transportation: Jackson, MS, USA, 1999.

19. Dongre, R.; D'Angelo, J. Evaluation of Different Parameters for Superpave High Temperature Binder Specification Based on Rutting Performance in the Accelerated Loading Facility at FHWA; Transportation Research Board: Washington, DC, USA, 2003.

20. Marasteanu, M.; Zofka, A.; Turos, M.; Li, X.; Velasquez, R.; Li, X. Investigation of Low Temperature Cracking in Asphalt Pavements; Minnesota Department of Transportation: Saint Paul, MN, USA, 2007.

21. Soltani, M.; Moghaddam, T.B.; Karim, M.R.; Baaj, H. Analysis of fatigue properties of unmodified and polyethylene terephthalate modified asphalt mixtures using response surface methodology. Eng. Fail. Anal. 2015, 58, 238-248. [CrossRef]

22. Zhen, L.; Sreeram, A.; Padhan, R.K.; Zhifei, T. Value-added application of waste PET based additives in bituminous mixtures containing high percentage of reclaimed asphalt pavement (RAP). J. Clean. Prod. 2018, 196, 615-625. [CrossRef]

23. Abdel-Goad, M.A.H. Waste polyvinyl chloride-modified bitumen. J. Appl. Polym. Sci. 2006, 101, 1501-1505. [CrossRef]

24. Hamedi, G.H. Effects of Polymeric Coating the Aggregate Surface on Reducing Moisture Sensitivity of Asphalt Mixtures. Int. J. Civ. Eng. 2018, 16, 1097-1107. [CrossRef]

25. Arabani, M.; Yousefpour Taleghani, M. Rutting behavior of hot mix asphalt modified by polyvinyl chloride powder. Pet. Sci. Technol. 2017, 35, 1621-1626. [CrossRef]

26. Colbert, B.W. The Perofrmance and Modification of Recycled Electronic Waste Plastics for the Improvement of Asphalt Pavement Materials. Master's Thesis, Michigan Technological University, Houghton, MI, USA, 2012.

27. Colbert, B.W.; Zhanping, Y. Properties of modified asphalt binders blended with electronic waste powders. J. Mater. Civ. Eng. 2012, 24, 1261-1267. [CrossRef]

28. Rosli Mohd Hasan, M.; Colbert, B.; Zhanping, Y.; Jamshidi, A.; Heiden, P.A.; Hamzah, M.O. A simple treatment of electronic-waste plastics to produce asphalt binder additives with improved properties. Constr. Build. Mater. 2016, 110, 79-88. [CrossRef]

29. Tapkin, S.; Cevik, A.; Uşar, Ü. Prediction of Marshall test results for polypropylene modified dense bituminous mixtures using neural networks. Expert Syst. Appl. 2010, 37, 4660-4670. [CrossRef]

30. Garcia-Morales, M.; Partal, P.; Navarro, F.J.; Gallegos, C. Effect of waste polymer addition on the rheology of modified bitumen. Fuel 2006, 85, 936-943. [CrossRef]

31. Al-Hadidy, A.I.; Tan, Y.-q. Effect of polyethylene on life of flexible pavements. Constr. Build. Mater. 2009, 23, 1456-1464. [CrossRef] 
32. Hinislioglu, S.; Agar, E. Use of waste high density polyethylene as bitumen modifier in asphalt concrete mix. Mater. Lett. 2004, 58, 267-271. [CrossRef]

33. González, O.; Peña, J.J.; Muñoz, M.E.; Santamaría, A.; Pérez-Lepe, A.; Martínez-Boza, F.; Gallegos, C. Rheological techniques as a tool to analyze polymer-bitumen interactions: Bitumen modified with polyethylene and polyethylene-based blends. Energy Fuels 2002, 16, 1256-1263. [CrossRef]

34. Pérez-Lepe, A.; Martínez-Boza, F.J.; Gallegos, C.; González, O.; Muñoz, M.E.; Santamaría, A. Influence of the processing conditions on the rheological behaviour of polymer-modified bitumen. Fuel 2003, 82, 1339-1348. [CrossRef]

35. Envisage Works. 2016-2017 Australian Plastics Recycling Survey. 2018. Available online: https:/www.environment.gov.au/protection/waste-resource-recovery/publications/australian-pl astics-recycling-survey-report-2017-18 (accessed on 1 September 2020).

36. Commonwealth of Australia. Environment and Communications References Committee; Commonwealth of Australia: Canberra, Australia, 2018.

37. Blue Environment. Data on Exports of Recylables from Australia to China. 2018. Available online: https://www.blueenvironment.com.au/export-of-recyclables-to-china/ (accessed on 1 September 2020).

38. Gonzalez, O.; Munoz, M.E.; Santamaria, A. Bitumen/polyethylene blends: Using m-LLDPEs to improve stability and viscoelastic properties. Rheol. Acta 2006, 45, 603-610. [CrossRef]

39. Standards Australia. Bitumen for Pavements Sydney; Standards Australia: Sydney, Australia, 2013.

40. AASHTO. Specification for Performance-Graded Asphalt Binder Using Multiple Stress Creep Recovery (MSCR) Test; AASHTO M332:2014; AASHTO: Washington, DC, USA, 2014.

41. Holtrop, W. Sprayed Sealing Practice in Australia. In Proceedings of the 1st Sprayed Sealing Conference, Adelaide, Australia, 27-29 July 2008.

42. Dack, S. Performance Seals-15 Years' experience in the use of S35E PMBs. In Proceedings of the 1st Sprayed Sealing Conference-Cost Effective High Performance Surfacings, Adelaide, Austrlia, 27-29 July 2008.

43. Austroads. Specification Framework for Polymer Modified Binders Austorads; AGPT-T190; Austroads: Sydney, Australia, 2019.

44. Austroads. Review of Australasian and Overseas Specifications and Performance Tests for Bitumens; Austroads: Sydney, Australia, 2016.

45. Standards Australia. Determination of the Effect of Heat and Air on a Moving Film of Bitumen (Rolling thin Film Oven (RTFO) Test); AS/NZS 2341.10:2015; Standards Australia: Sydney, Australia, 2015.

46. Ali, A.H.; Mashaan, N.S.; Karim, M.R. Investigations of Physical and Rheological Properties of Aged Rubberised Bitumen. Adv. Mater. Sci. Eng. 2013, 2013, 239036. [CrossRef]

47. Bondt, A.H.; Plug, C.P. A Brief Introduction to Polymer Modified Bitumen (PMB): OOMs Civiel bv. 2014. Available online: https://ooms.nl/ (accessed on 1 September 2020).

48. AASHTO. Specification for Performance-Graded Asphalt Binder Using Multiple Stress Creep Recovery (MSCR) Test; AASHTO MP19:2010; American Association of State Highway and Transportation Officials: Washington, DC, USA, 2010.

49. Ben, P. Using HDPE Waste Polymer to Enhance the Rutting Ressitnace of Bituemnous Binder. Bachelor's Thesis, Curtin University, Perth, Australia, 2019.

(C) 2020 by the authors. Licensee MDPI, Basel, Switzerland. This article is an open access article distributed under the terms and conditions of the Creative Commons Attribution (CC BY) license (http://creativecommons.org/licenses/by/4.0/). 